\title{
Unusual presentation of a first branchial arch fistula with maxillofacial infection: a case report
}

\author{
Yu Han ${ }^{1 \dagger}$, Run-qin Yang ${ }^{1 \dagger}$, Liu Hong ${ }^{2 \dagger}$, Cui-ping Zhong ${ }^{3}$ and Ding-jun Zha ${ }^{1 *}$
}

\begin{abstract}
Background: First branchial cleft anomaly (FBCA) is a rare congenital defect that arises due to incomplete closure of the ventral portion of the first and second branchial arches. There are variable complex clinical manifestations for patients with FBCA, which are prone to misdiagnosis and inadequate treatment. FBCAs usually involve the facial nerve with a consequent increased risk of facial nerve damage. Here, we present an unusual case of FBCA presenting with two preauricular pits in association with an abnormal maxillofacial cyst.

Case presentation: A 10-month-old girl presented to our department due to recurrent maxillofacial infections accompanied by swelling or abscess of the left cheek and purulent discharge from the preauricular pit for 4 months. A 3D-computed tomography (CT) fistulogram and magnetic resonance imaging (MRI) revealed two conjunctive tract lesions: one tract arose from the skin surface anteroinferior to the external auditory canal (EAC), through the deep lobe of the left parotid, and anteriorly extended to the left masseter; the other extended from the superficial lobe of the left parotid to the intertragic notch. After the maxillofacial infection was controlled by intravenous antibiotic administration, surgery was performed. Intraoperative tools, such as facial nerve monitors, microscopes, and methylene blue dyes, were used to facilitate the complete dissection and protection of the facial nerve. On follow-up over one year, the patient recovered well without facial palsy or recurrence.
\end{abstract}

Conclusion: FBCA with maxillofacial cysts is rare and prone to misdiagnosis. Physicians should pay attention to this anatomic variant of FBCA with the fistula track located deep inside the facial nerve and projected medially to the masseter.

Keywords: First branchial cleft anomalies, Facial nerve, Maxillofacial, Case report

\section{Background}

First branchial cleft anomalies (FBCAs) are rare congenital defects that account for less than $8-10 \%$ of all branchial cleft anomalies and arise due to incomplete closure of the ventral portion of the first and second branchial arches $[1,2]$. A number of classification systems have been developed in an attempt to assist preoperative assessment and surgical planning for FBCAs.

*Correspondence: zhadjun@fmmu.edu.cn

†Yu Han, Run-qin Yang and Liu Hong have contributed equally to this work

1 Department of Otolaryngology, Xijing Hospital, Fourth Military Medical University, Xi'an 710032, Shaanxi Province, China

Full list of author information is available at the end of the article
Work's classification is the most common system based upon both anatomical and histological features. According to this classification, FBCAs are divided into two distinct types: type I has only ectodermal components and is usually superficial to the facial nerve and lies in close proximity to the ear; type II has ectodermal and mesodermal components, often lying medial to the facial nerve and communicating with the external auditory canal (EAC) [3]. Olsen et al. [4] also introduced a classification of defects into cysts, sinuses, or fistulas based on the number of surface openings present. To determine the relationship between FBCAs and the facial nerve prior to surgery, Liu et al. introduced a new subclassification for type II FBCAs into three subtypes based on

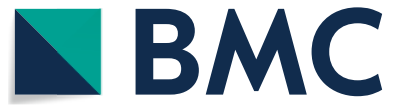

(c) The Author(s) 2021. Open Access This article is licensed under a Creative Commons Attribution 4.0 International License, which permits use, sharing, adaptation, distribution and reproduction in any medium or format, as long as you give appropriate credit to the original author(s) and the source, provide a link to the Creative Commons licence, and indicate if changes were made. The images or other third party material in this article are included in the article's Creative Commons licence, unless indicated otherwise in a credit line to the material. If material is not included in the article's Creative Commons licence and your intended use is not permitted by statutory regulation or exceeds the permitted use, you will need to obtain permission directly from the copyright holder. To view a copy of this licence, visit http://creativecommons.org/licenses/by/4.0/. The Creative Commons Public Domain Dedication waiver (http://creativeco $\mathrm{mmons}$.org/publicdomain/zero/1.0/) applies to the data made available in this article, unless otherwise stated in a credit line to the data. 
MRI findings [2]. A common location of FBCAs is the area from the EAC to the level of the hyoid bone. The opening of the fistula of FBCAs is typically located in the periauricular area, but more rare locations have also been reported, such as the EAC, middle ear cleft, postauricular region, and even within the neck over the angle of the mandible [5]. Usually, FBCAs have a close anatomical relationship to the facial nerve owing to their embryologic origin. D'Souza et al.[6] performed a comprehensive review of the literature and found that FBCAs had diversiform patterns with the facial nerve; they can be lateral to, medial to, or between branches of the facial nerve. Patients presenting at a younger age were more likely to have a deep tract with a consequent increased risk of facial nerve damage. Thus, treatment for FBCAs is complicated by both variable tract lesions and the complex anatomical relationship to the facial nerve. In this article, we describe a paediatric case of an exceptional type II FBCA presenting with two preauricular pits in association with an abnormal maxillofacial cyst and a tract that passes into the deep lobe of the parotid gland and extends anteriorly to the masseter.

\section{Case presentation}

We obtained written informed consent from the patient's parents. The case is compliant to the SCARE guidelines [7]. A 10-month-old girl was taken to our hospital by her parents due to recurrent maxillofacial infections accompanied by swelling or abscess of the left cheek and purulent discharge from the preauricular pit for 4 months. On physical examination, a swollen erythematous maxillofacial lesion was observed in the left cheek (Fig. 1). A pit with white purulent secretions in the intertragic notch and another small cutaneous dimple in the left parotid gland region were observed (Fig. 1A). EAC contained no fistula track. All other head and neck examinations were unremarkable. Ultrasound performed for the maxillofacial area demonstrated a lesion with inflammatory changes. The other auxiliary examinations, including otoscopy, pure tone audiometry and renal ultrasound, were without abnormalities. There was no history of previous incision or drainage procedures. No particular family history was recorded. A 3D-computed tomography (CT) fistulogram and magnetic resonance imaging (MRI) were performed to delineate the course of the tract and the extent of the lesion. The results revealed two conjunctive tracts: one tract arose from the skin surface anteroinferior to the EAC, beneath the facial nerve, and passed into the deep lobe of the parotid gland and projected to the masseter; the other tract extended from the superficial lobe of the left parotid to the intertragic notch (Figs. 2 and $3 \mathrm{~A}-\mathrm{C}$ ).

Originally, the infection could be controlled by intravenous antibiotic administration, which resulted in maxillofacial infection improvement (Fig. 1B). However, recurrent inflammation had been persisting for one year. Finally, after obtaining parental consent, the patient underwent surgical management under general anaesthesia at 2 years old. The surgery was performed under facial nerve monitoring. First, a methylene blue staining
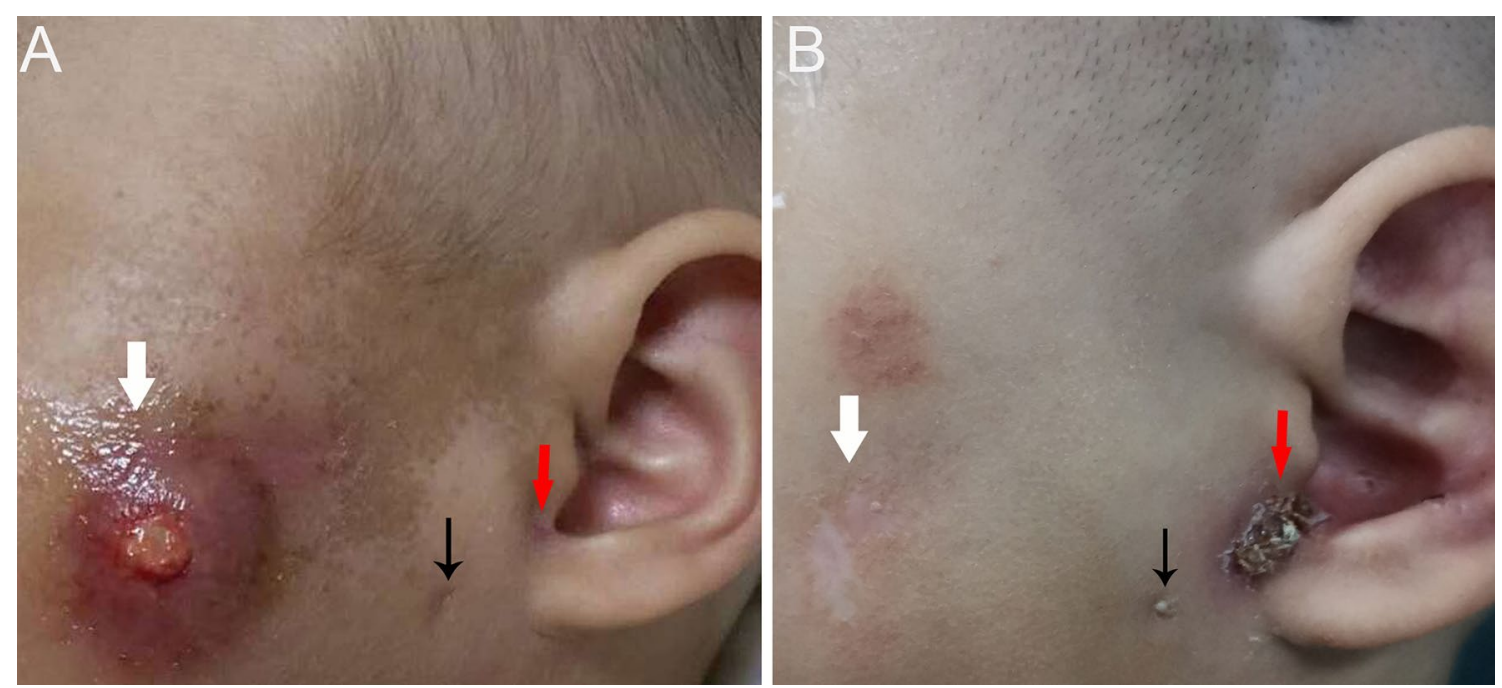

Fig. 1 First branchial cleft anomalies presenting as two preauricular pits associated with an abnormal maxillofacial cyst. One pit with purulent secretions is in the intertragic notch (red arrow), and another small cutaneous dimple (black arrow) is shown in the left cheek region. The maxillofacial infection with abscess resolved with conservative treatment. A The black arrow indicates the cutaneous dimple before treatment, and B the black arrow shows the same region post-treatment 


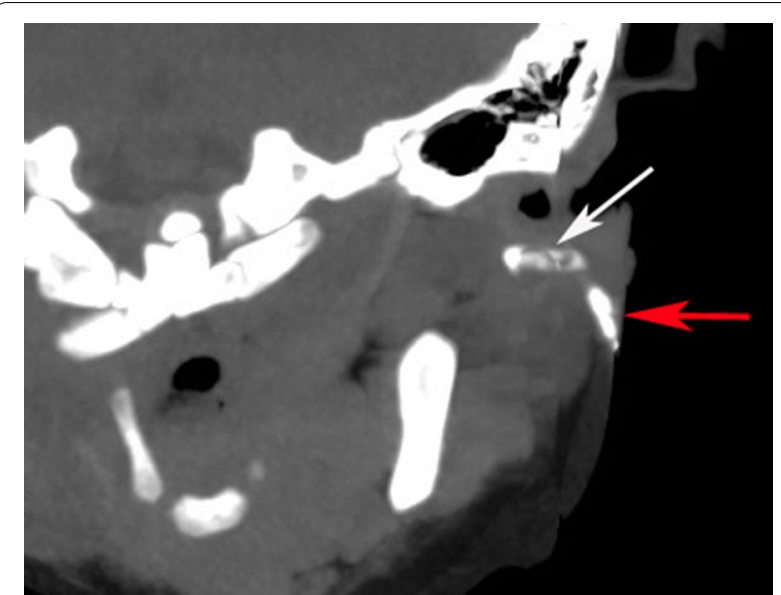

Fig. 2 3D-coronal computed tomography fistulogram scans are shown. Low osmolar nonionic iodinated contrast was injected through the intertragic notch dimple, revealing two tracts, one extending anteriorly to the left masseter (white arrow) and another lying in the superficial lobe of the left parotid (red arrow)

agent was injected into the cutaneous pit of the intertragic notch. Then, a modified Blair incision encompassing the pit was made. The facial nerve was identified first, which allowed the cyst to be incised easily. During superficial parotidectomy, one cyst lying in the superficial lobe of the parotid and cartilage of the intertragic notch were removed. Blunt dissection was then used to follow the other larger fistula tract, which was located deep inside the facial nerve and projected medially to the posterior aspect of the masseter (Fig. 4A). Using a microscope, the tract was carefully separated from the facial nerve, which formed a blind pouch alongside the masseter (Fig. 4B). Finally, a suction drain was placed and kept until $48 \mathrm{~h}$ postoperatively (Fig. 4C). The patient recovered well, and no complications occurred in the following days. The final pathology of the excised tissue was consistent with that of type II FBCA (Fig. 4D). At follow-up over one year postoperatively, the surgical site was well healed, and the patient had no facial palsy or recurrence by coronal and axial MRI imaging (Fig. 3D-F).

\section{Discussion and conclusions}

Branchial anomalies arise when the branchial arches and their associated clefts or pouches fail to regress or develop normally [8]. FBCAs are relatively uncommon, and there are various clinical manifestations in patients. As shown in Table 1, FBCAs can appear at any age, and the tract may extend to the osteocartilaginous junction of the ear canal, Eustachian tube, submandibular gland, pharyngeal cavity, and digastric muscle [1,9-14]. Muranishi et al. [15] also reported a case of FBCA that was clinically typical but occult in images and pathology. In our case, repetitive inflammation around the maxillofacial region was observed. The unusual cord structure beneath the facial nerve, which passed into the deep lobe of the parotid gland, projected to the masseter. This rare case of type II FBCA is prone to misdiagnosis and inadequate

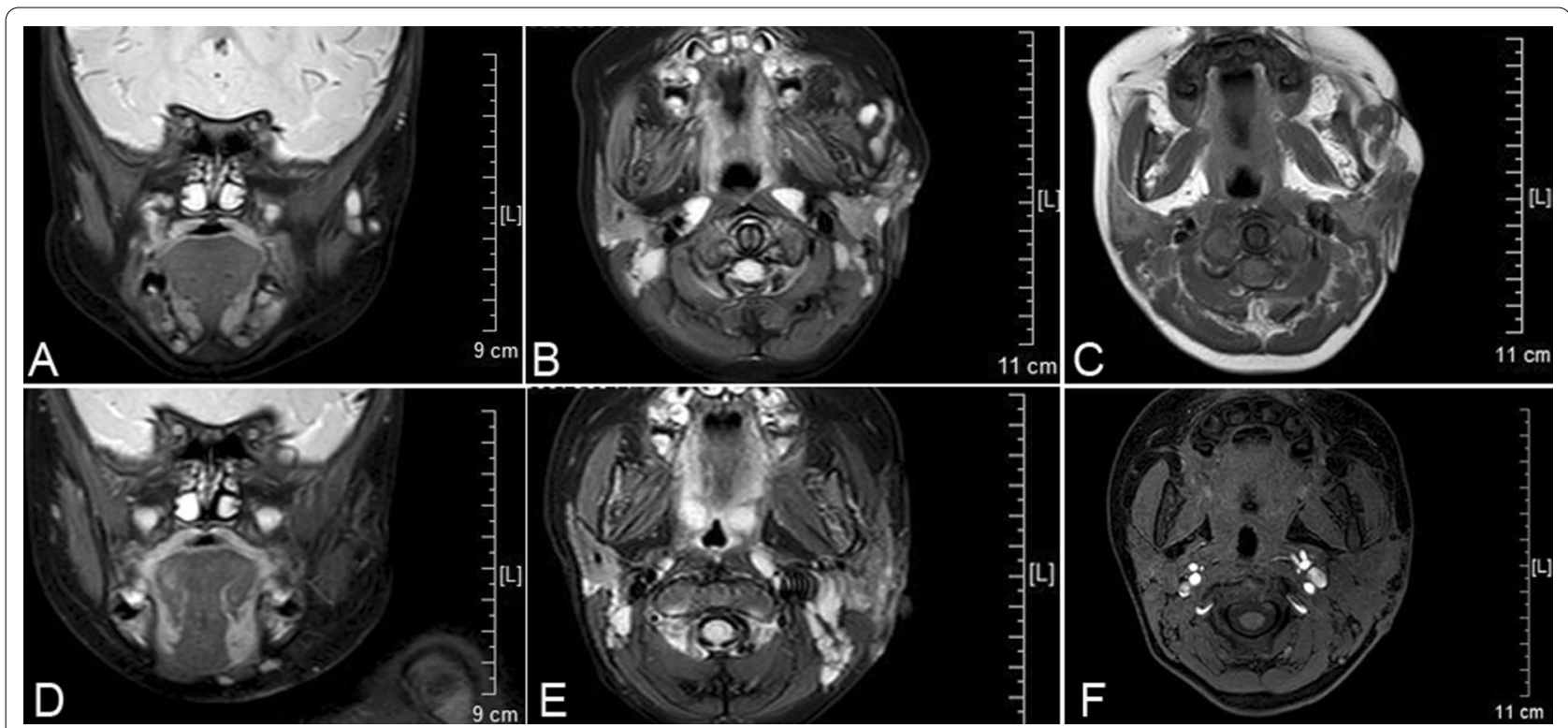

Fig. 3 Magnetic resonance imaging (MRI) is shown. Before surgery treatment, coronal T2 weighted MRI (A), axial T2 weighted MRI (B) and axial T1 weighted MRI (C) reveal the location of a mass centred between the masseter muscle and left parotid gland. At follow-up over one year postoperatively, coronal T2 weighted image (D), axial T2 weighted image (E) and 3D mDIXON-axial fat suppressed T1 weighted image (F) confirm there is no recurrence on the primary site of the lesion 

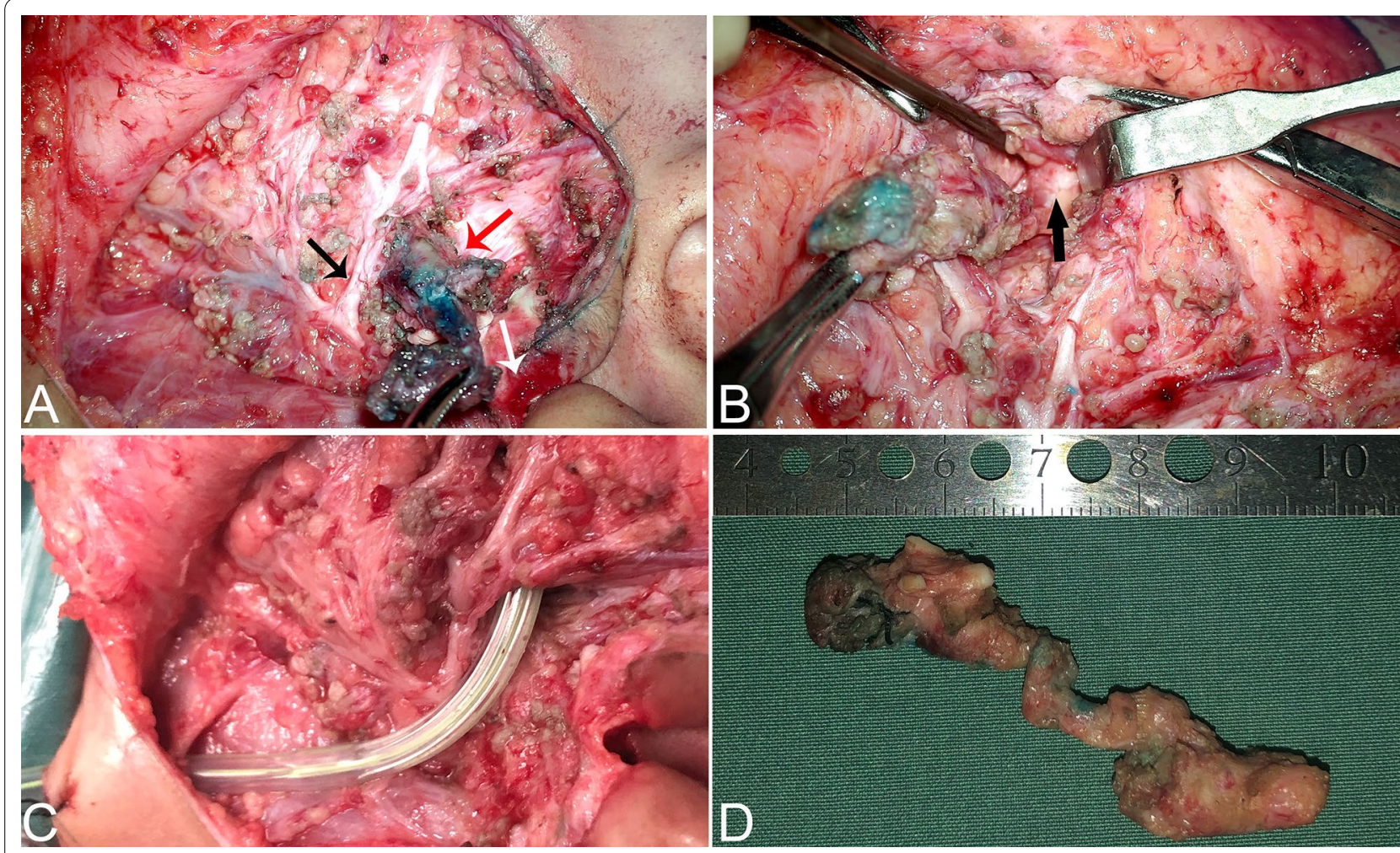

Fig. 4 Intraoperative findings and surgical strategy. A The facial nerve was identified during surgery. The larger tract (red arrow) projecting medially deep within the temporal trunk of the facial nerve (black arrow) and the smaller tract ending at the cartilage of the intertragic notch (white arrow) are shown. B The black arrow indicates the lesion boundary as a blind pouch lying tightly along the masseter. C A suction drain was placed into the tract tunnel after the first branchial cleft anomaly excision. D A specimen containing cartilage post-removal is shown. The complete fistula was approximately $6 \mathrm{~cm}$ in length

Table 1 Representative clinical manifestations of FBCA patients

\begin{tabular}{|c|c|c|c|c|}
\hline Author & Date & Age & Complaints of presentation & Description the course of FBCAs \\
\hline Fastenberg [9] & 2016 & 3-year-old & $\begin{array}{l}\text { Pain in the right ear and swelling in the postauricular } \\
\text { area }\end{array}$ & $\begin{array}{l}\text { A fistula track into the osteocartilaginous junction of } \\
\text { the ear canal }\end{array}$ \\
\hline Faruque [10] & 2019 & 12-year-old & A draining cervical pit & Fistulas opening to the Eustachian tube \\
\hline Watanabe [11] & 2017 & 14-month-old & Redness and swelling in the left neck area & $\begin{array}{l}\text { Fistula extending from a cutaneous opening in the left } \\
\text { submandibular area penetrating the submandibular } \\
\text { gland, and ending in the pharyngeal cavity }\end{array}$ \\
\hline Fanous [1] & 2020 & 6-year-old & $\begin{array}{l}\text { Left conductive hearing loss and an ipsilateral painful } \\
\text { cervical mass }\end{array}$ & $\begin{array}{l}\text { A presumed ear canal cholesteatoma in association } \\
\text { with an abnormal bony canal and a pharyngeal cyst }\end{array}$ \\
\hline Chaouki [12] & 2021 & 3-year-old & Recurrent right lateral cervical infection & $\begin{array}{l}\text { A fistulous path underthe facial nerve and ends under } \\
\text { the digastric muscle }\end{array}$ \\
\hline Roche [13] & 2016 & 4-year-old & $\begin{array}{l}\text { Recurrent left neck abscesses and palpable persistent } \\
\text { submandibular swelling }\end{array}$ & $\begin{array}{l}\text { Duplication of the external ear canal running medial to } \\
\text { the facial nerve }\end{array}$ \\
\hline Zhang [14] & 2020 & 19-year-old & $\begin{array}{l}\text { A mass behind the right earlobe and recurrent post- } \\
\text { auricular swelling and pain }\end{array}$ & $\begin{array}{l}\text { The mass originated from the stylomastoid foramen } \\
\text { and adhered to the posterior surface of the parotid } \\
\text { gland, invading the temporal bone }\end{array}$ \\
\hline Muranishi [15] & 2020 & 8-year-old & An infectious epidermal cyst & $\begin{array}{l}\text { A cord structure attached to subcutaneous tissue at } \\
\text { the intertragal notch, no opening to the external } \\
\text { auricular canal }\end{array}$ \\
\hline
\end{tabular}


treatment. Although this patient had two preauricular pits, the lesion was distinct from congenital preauricular fistula, which is more common and arise from failure of fusion of the auricular hillocks of His instead of the branchial arches [16]. In addition, some rare syndrome diseases, such as Branchio-oto-renal syndrome (BORS) or Goldenhar syndrome, may be accompanied by branchial cleft anomalies. However, these diseases are usually autosomal dominant disorders with abnormalities in multiple organ systems $[17,18]$. For example, the typical manifestations of BORS are hearing loss, abnormal branchial cleft development, and renal dysplasia, while patients with Goldenhar syndrome usually present with the presence of congenital cholesteatoma, branchial cleft anomalies and facial nerve abnormalities. Although FBCAs can exhibit different patterns, they are rarely associated with other facial malformations [19]. However, errors in the development of the first branchial cleft can result in duplication anomalies of the external auditory canal [20]. In a few cases, FBCAs are accompanied by microtia, stenosis or atresia of EAC, and cholesteatoma [21-23]. Therefore, the diagnosis of FBCAs is challenging, and doctors should be aware of possible anatomic variants for this disease and keep in mind the differential diagnosis of some rare syndromes.

Once FBCA is diagnosed, surgical excision is the definitive treatment choice. However, choosing the optimal surgical time and surgical approach is very important. As reported, recurrence rates were as high as $20 \%$ when excision was performed in the acutely inflamed stage [24]. Repeated infection in the lesion might result in inflammatory adhesion in surrounding tissues and cause structures to be difficult to identify, which may increase the risk of recurrence and injury to the facial nerve. Thus, surgical excision should be considered after the infection has resolved. Additionally, age is another factor affecting surgical treatment. As previous studies have reported, the anatomy of infants differs from those of older children and adolescents. The facial nerve of younger children is more superficial and delicate than that of older children and adults, which makes surgical treatment challenging. Furthermore, younger patients are more likely to have lesions deep to the facial nerve, and the facial nerve injury rate ranges from 10 to $25 \%$ in paediatric patients undergoing FBCA resection [25]. Thus, we agree with the opinion that surgeons should weigh the risks and benefits of surgery with care when patients are less than 1 year old [26]. Moreover, in most FBCA cases, a parotidectomy approach with preliminary identification of the facial nerve and excision of the entire tract is necessary. Patients with FBCAs often concurrently present with otologic complaints, and they may require ear-specific surgery such as tympanoplasty or canalplasty [27]. Additionally, methylene blue dye injection during surgery may help verify the suspected path of a fistula, and intraoperative microscopy and facial nerve monitoring are indispensable for protecting the facial nerve. These methods have the potential to reduce facial nerve injury and recurrence rates.

In summary, we described an unusual presentation of type II FBCA with maxillofacial infection, and the main fistulous tract travelled medial to the facial nerves into the deep lobe of the parotid gland and extended anteriorly to the masseter. Surgical excision should be performed after the resolution of any infection as it is important for identification of the facial nerve in almost all cases, especially in young patients. Intraoperative tools, such as facial nerve monitors, microscopes, and methylene blue dyes, facilitate the complete dissection and protection of the facial nerve.

\section{Abbreviations}

FBCA: First branchial cleft anomaly; FBCAs: First branchial cleft anomalies; EAC: External auditory canal; MRIs: Magnetic resonance images.

\section{Acknowledgements \\ Not applicable.}

\section{Authors' contributions}

YH was responsible for writing the paper, RY collected and analyzed the clinical data, LH revised and edited the manuscript, CZ took part in following up the patient and DZ took responsibility for the integrity of the content of the manuscript. All authors read and approved the final manuscript.

\section{Funding}

This study was supported by the National Natural Scientific Foundation of China (Grant No. 81870719), the Nature Science Foundation of Shaanxi Province (Grant No.2018SF-240) and the Research Promotion Project from Xijing Hospital (XJZT19ML01). The funder was supported by YH. The fundings had no role in study design, collection, analysis or interpretation of data, or manuscript preparation.

\section{Availability of data and materials \\ Not applicable.}

\section{Delarations}

\section{Ethics approval and consent to participate}

Ethical approval Ethical approval was given by the medical ethics committee of the First Affiliated Hospital of the Air Force Medical University under number KY20212022-C-1.

\section{Consent for publication}

Written informed consent was obtained from the patient's parent.

\section{Competing interests}

The authors declare no competing interests.

\section{Author details}

${ }^{1}$ Department of Otolaryngology, Xijing Hospital, Fourth Military Medical University, Xi'an 710032, Shaanxi Province, China. ${ }^{2}$ State Key Laboratory of Cancer Biology, National Clinical Research Center for Digestive Diseases, and Xijing Hospital of Digestive Diseases, Fourth Military Medical University, Xi'an 710032 Shaanxi Province, China. ${ }^{3}$ Department of Otolaryngology Head and Neck Surgery, the 940Th Hospital, Lanzhou 730050, Gansu Province, China. 
Received: 3 April 2021 Accepted: 29 June 2021

Published online: 03 July 2021

\section{References}

1. Fanous A, Couloigner V, Gorphe P, Galmiche L, Alexandru M, Garabedian EN, et al. Unusual presentation of a first branchial cleft cyst associated with an abnormal bony canal — a case report. J Otolaryngol Head Neck Surg. 2020;49(1):32.

2. Liu W, Chen M, Liu B, Zhang J, Ni X. Clinical analysis of type II first branchial cleft anomalies in children. Laryngoscope. 2021;131(4):916-20.

3. Work WP. Newer concepts of first branchial cleft defects. Laryngoscope. 1972;82(9):1581-93.

4. Olsen KD, Maragos NE, Weiland LH. First branchial cleft anomalies. Laryngoscope. 1980;90:423-36.

5. Panchbhai AS, Choudhary MS. Branchial cleft cyst at an unusual location: a rare case with a brief review. Dentomaxillofac Radiol. 2012;41(8):696-702

6. D'Souza AR, Uppal HS, De R, Zeitoun H. Updating concepts of first branchial cleft defects: a literature review. Int J Pediatr Otorhinolaryngol. 2002;62(2):103-9.

7. Agha RA, Franchi T, Sohrabi C, Mathew G, Kerwan A, Thoma A, et al. The SCARE 2020 Guideline: Updating Consensus Surgical CAse REport (SCARE) Guidelines. Int J Surg. 2002;84:226-30.

8. Waldhausen JH. Branchial cleft and arch anomalies in children. Semin Pediatr Surg. 2006;15(2):64-9.

9. Fastenberg J, Nassar M. First branchial cleft cyst. N Engl J Med. 2016;375(16):e33.

10. Faruque O, Wischhusen JD, Reckley LK, Rooks VJ, Liming BJ. First branchial cleft fistula (Work Type 2) with an internal opening to the Eustachian tube: case report and review of literature. Radiol Case Rep. 2019:14(7):819-24.

11. Watanabe T, Shimizu T, Ohno M, Fuchimoto Y, Mizutari K, Morimoto N, et al. An unusual presentation of branchial cleft fistula penetrating the submandibular gland. Int J Pediatr Otorhinolaryngol Extra. 2017;18:13-5.

12. Chaouki A, Lyoubi M, Lahjaouj M, Rouadi S, Mahtar M. Atypical first branchial cleft fistula: a case report. Int J Surg Case Rep. 2021;78:159-61.

13. Roche P, Saunders S, Naunheim M, Kovach A, Herrington H, Robson CD, et al. First branchial cleft anomaly presenting with a complete duplication of the external auditory canal—a photo anatomic review. Int J Pediatr Otorhinolaryngol Extra. 2016:12:1-4.

14. Zhang CL, Li CL, Chen HQ, Sun Q, Liu ZH. First branchial cleft cyst accompanied by external auditory canal atresia and middle ear malformation: a case report. World J Clin Cases. 2020;8(16):3616-20.
15. MuranishiY, Nishimoto $S$, Kawai K, Ishise $H$, Kakibuchi M. An occult case of the first branchial cleft anomaly. J Surg Case Rep. 2020;2020(9):rjaa291.

16. Matev B, Lyutfi E, Stoyanov GS, Sapundzhiev NR. Preauricular sinus: a tale of forgetful rediscovery. Cureus. 2020;12(6):e8885.

17. Shen LF, Zhou SH, Chen QQ, Yu Q. Second branchial cleft anomalies in children: a literature review. Pediatr Surg Int. 2018;34(12):1251-6.

18. Kabak SL, Savrasova NA, Zatochnaya VV, Melnichenko YM. Hemifacial microsomia: skeletal abnormalities evaluation using CBCT (case report). J Radiol Case Rep. 2019;13(11):1-9.

19. Triglia JM, Nicollas R, Ducroz V, Koltai PJ, Garabedian EN. First branchial cleft anomalies: a study of 39 cases and a review of the literature. Arch Otolaryngol Head Neck Surg. 1998;124(3):291-5.

20. Blevins NH, Byahatti SV, Karmody CS. External auditory canal duplication anomalies associated with congenital aural atresia. J Laryngol Otol. 2003; 117(1):32-8.

21. Abdollahi Fakhim S, Naderpoor M, Mousaviagdas M. First branchial cleft fistula associated with external auditory canal stenosis and middle ear cholesteatoma. Iran J Otorhinolaryngol. 2014;26(77):263-6.

22. Banakis Hartl RM, Said S, Mann SE. Bilateral ear canal cholesteatoma with underlying type I first branchial cleft anomalies. Ann Otol Rhinol Laryngol. 2019;128(4):360-4.

23. Yalçin S, Karlidağ T, Kaygusuz I, Demirbağ E. First branchial cleft sinus presenting with cholesteatoma and external auditory canal atresia. Int J Pediatr Otorhinolaryngol. 2003;67(7):811-4.

24. Martinez Del Pero M, Majumdar S, Bateman N, Bull PD. Presentation of first branchial cleft anomalies: the Sheffield experience. J Laryngol Otol. 2007:121(5):455-9.

25. Li W, Zhao L, Xu H, Li X. First branchial cleft anomalies in children: Experience with 30 cases. Exp Ther Med. 2017:14(1):333-7.

26. Brown LA, Johnston DR, Rastatter J, Sweis BM, Maddalozzo J. Differences in management outcome for first branchial cleft anomalies: a comparison of infants and toddlers to older children. Int J Pediatr Otorhinolaryngol. 2019:122:161-4.

27. Shinn JR, Purcell PL, Horn DL, Sie KC, Manning SC. First branchial cleft anomalies: otologic manifestations and treatment outcomes. Otolaryngol Head Neck Surg. 2015;152(3):506-12.

\section{Publisher's Note}

Springer Nature remains neutral with regard to jurisdictional claims in published maps and institutional affiliations.
Ready to submit your research? Choose BMC and benefit from:

- fast, convenient online submission

- thorough peer review by experienced researchers in your field

- rapid publication on acceptance

- support for research data, including large and complex data types

- gold Open Access which fosters wider collaboration and increased citations

- maximum visibility for your research: over 100M website views per year

At BMC, research is always in progress.

Learn more biomedcentral.com/submissions 